\title{
Supporting decision-making for channel conveyance maintenance
}

\author{
Marta Roca ${ }^{1, a}$, Adrian Rushworth ${ }^{2}$ and Dave Dennes ${ }^{2}$ \\ ${ }^{1} \mathrm{HR}$ Wallingford, Howbery Park, Wallingford, OX108BA, United Kingdom \\ ${ }^{2}$ Environment Agency, Deanrey Rd, Bristol, BS15AH, United Kingdom
}

\begin{abstract}
Channel maintenance activities, understood as vegetation and sediment management, have a potential to change the conveyance capacity of a watercourse and thus, to provide a benefit from a flood risk perspective. Vegetation and its overgrowth is one of the main factors influencing flow capacity and hence river conveyance. Despite the undesirable consequences associated with flooding, it is rare that sufficient funds are available to undertake all necessary maintenance activities. In the face of limited budgets, flood risk managers must take difficult decisions in order to decide how and where limited resources should be invested. This paper presents a national scale approach to identify the strategically important watercourses where conveyance related works produce the greatest benefit. This is done by identifying watercourses where maintenance works may have a potential to positively maintain or increase conveyance capacity and watercourses where the attribution of area or receptors benefiting is important. Assembling together this information produces a picture of the strategic lengths of watercourse to be maintained.
\end{abstract}

\section{Introduction}

Conveyance is a quantitative measure of the discharge capacity of a watercourse. It relates the total discharge to a measure of the gradient slope of the channel

$$
K=Q / S^{1 / 2}
$$

where $K(\mathrm{~m} 3 / \mathrm{s})$ is the conveyance, $Q(\mathrm{~m} 3 / \mathrm{s})$ is the discharge and $S$ is the uniform gradient. The ability of a channel to convey water flow directly influences water levels and thus, flooding conditions of surrounding areas (Figure 1). For example, an increase of flow resistance involves smaller flow velocities and greater water depths.

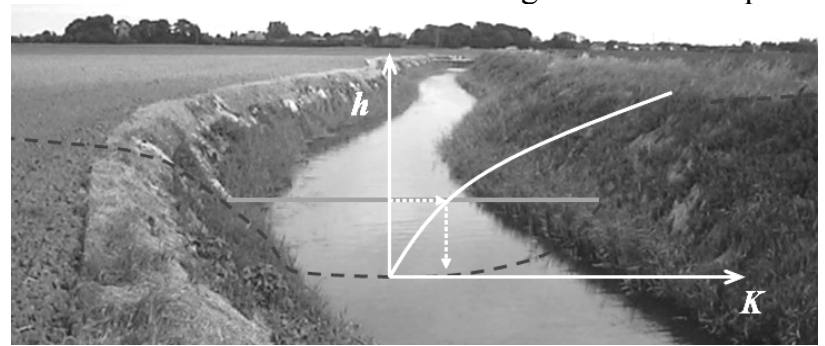

Figure 1. Relation between water level (h) and conveyance $(\mathrm{K})$

Flood risk management agencies spend a large amount of their budgets maintaining the conveyance capacity of river channels. Conveyance management implicitly is based on the idea of maintaining or ensuring

\footnotetext{
${ }^{\mathrm{a}}$ Corresponding author: mrt@hrwallingford.com
}

a certain condition of the channel with the aim to contain water discharges up to a certain level, thus to ensure a certain standard of protection. In man-made flood assets or artificial channels, both the condition and standard of protection are defined in the design process, monitored and recorded as a characteristic of the asset. This, however, does not occur in natural channels.

Vegetation and its overgrowth is one of the main factors influencing channel capacity (Figure 2). Sediment deposits can also impact watercourse conveyance by reducing flow area. Maintenance works such as vegetation cutting, dredging and desilting aim to maintain or improve channel conveyance capacity. Inadequate capacity of watercourses exposes communities and critical infrastructure to severe damages.

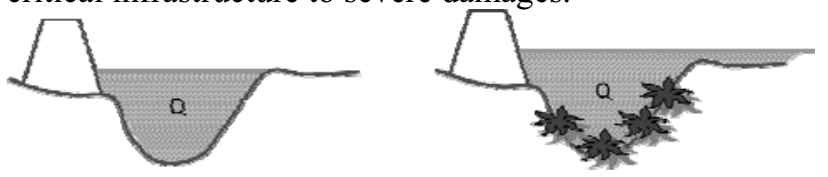

Figure 2. Increase of water levels in the channel (right) for the same water discharge due to increased channel vegetation

Despite the undesirable consequences associated with flooding, the effective management of conveyance represents a considerable challenge to flood risk managers given the financial burden associated with 
maintenance and the implication of not providing adequate protection to exposed communities.

This paper presents a national scale approach to identify the strategically important watercourses where conveyance related works produce the greatest benefit. Chapter 2 describes the overall methodology that consists on identifying watercourses where maintenance works may have a potential to positively maintain or increase conveyance capacity and watercourses where the attribution of area or receptors benefiting is important. Chapter 3 focuses on how the impacts of conveyance are quantified and Chapter 4 describes the estimation of the benefits of such maintenance works. The selection of the best management option is presented in Chapter 5 and Chapter 6 discusses the results.

The methodology presented is aimed to provide a national overview of the likely conveyance management works required to provide a particular level of benefits although it is noted that local particularities cannot be considered by the method. The preferred management option and its benefits defined at each watercourse at a national scale constitute the baseline scenario against which the real Environment Agency maintenance programmes in UK can be compared and assessed.

\section{Overview of the method}

The general principle behind the analysis is to identify the strategically important watercourses where conveyance related works produce the greatest benefit. This is done identifying watercourses where maintenance works may have a potential to positively maintain or increase conveyance capacity (potential important maintained watercourses) and watercourses where the attribution of benefits is important (potential important benefitting watercourses). Assembling together the information of the potential important maintained and benefitting watercourses produces a picture of the strategic lengths of watercourse to be maintained. For example, maintenance works may have a very positive impact in one particular watercourse, reducing effectively water levels and increasing conveyance capacity, but without modifying the flood risk of adjacent properties and thus, not producing any benefit.

\subsection{General steps}

To identify the potential watercourses to be maintained the following steps (Figure 3) are necessary:

\subsubsection{Step 1: Define the relevant geometry and characteristics of main rivers in England}

Based on national datasets the geometry of the crosssection, the slope of the reach, and the type of substrate and vegetation, which determines the roughness coefficient, are defined for all the main watercourses in England. Main rivers are the ones where the Environment Agency carries out maintenance, improvement or construction works to manage flood risk. The River Habitat Survey (RHS) [1], a national database, is used to obtain this information although it is acknowledged that local information, when available, may provide more reliable and accurate inputs.

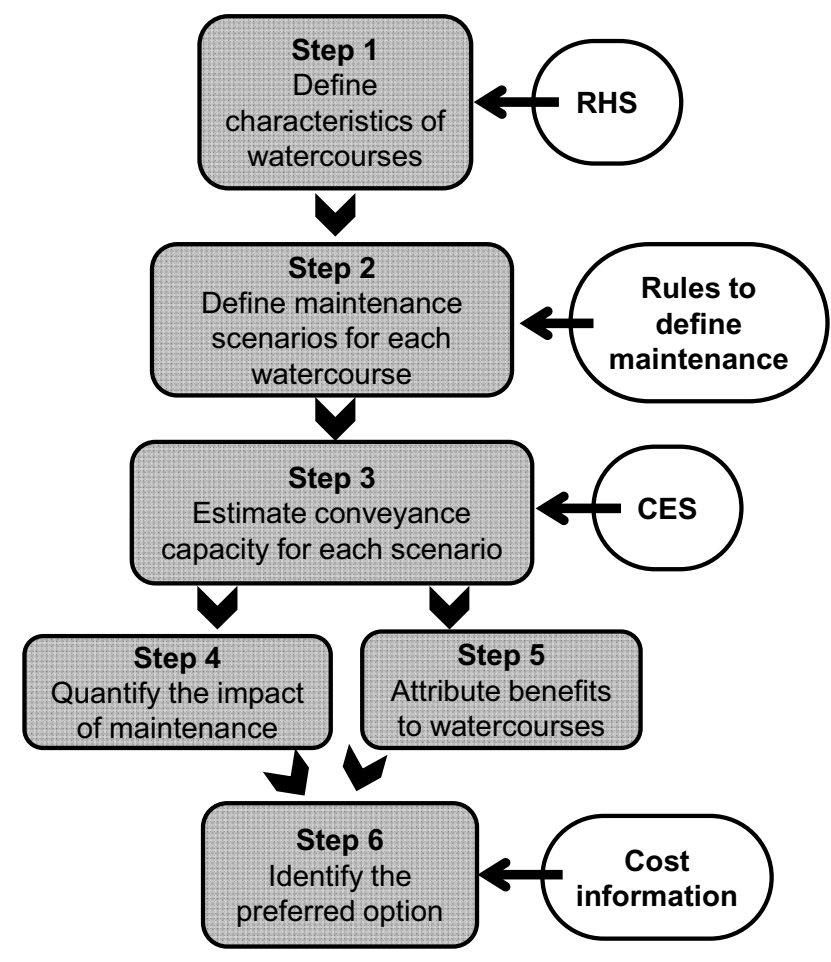

Figure 3. Methodological approach

\subsubsection{Step 2: Define maintenance scenarios (including vegetation and sediment management)}

Based on the characteristics of the watercourse and using existing guidance [2], rules are developed to estimate the possible management scenarios and the changes they cause on the characteristics of the watercourse (roughness coefficients and channel geometry).

\subsubsection{Step 3: Estimate the conveyance capacity of each maintenance scenario}

The conveyance capacity is estimated with an hydraulic model based on the characteristics of the watercourse (cross-section, slope, roughness) determined in Step 1. The Conveyance Estimation System, CES [3], has been used in this project. The rules developed in Step 2 are applied to modify the characteristics of the watercourse under each scenario. The main changes are related to roughness coefficients due to vegetation management and cross-sectional area due to sediment management. 


\subsubsection{Step 4: Quantify the impact of maintenance}

The change in conveyance capacity of the main channel (expressed as a percentage) is used to quantify the impacts of maintenance. This parameter is estimated for all watercourses in order to provide a simple and credible measure of the impacts of maintenance works.

\subsubsection{Step 5: Attribute benefits to different lengths of watercourses}

A simplified risk attribution methodology to watercourses is applied. Properties in the floodplain that are potential candidates to benefit from channel maintenance are assigned to river lengths of $50 \mathrm{~m}$. As we do not know which length of a watercourse will be responsible for flooding in any given impact cell, we need to assume that the closest watercourse is most likely. Assumptions about the flooding extension are made.

\subsubsection{Step 6: Identifying the preferred management option}

Combining the information from impacts of maintenance scenarios (Step 4) and attributed benefits (Step 5) and considering certain assumptions on costs of maintenance options, it is possible to identify the best management option at each river length.

\subsection{Conveyance management scenarios considered}

The management scenarios are defined as modifications of what is considered the baseline case. The baseline defines the cross-section shape and the type of substrate and vegetation at the channel bed and banks and is obtained from a national database, the River Habitat Survey (RHS). The management options applied to all rivers in England are presented in Table 1. This presents the baseline scenario (BL) provided by RHS and the assumptions about deposition of sediment and vegetation cutting options.

Option 1 is a "Do nothing" option with no vegetation management. It is considered that the watercourse is not prone to deposition and thus sediment management is not necessary. The cross-section shape and roughness values are defined by the information provided in the RHS database.

Option 2 is a "Do nothing" option related to sediment management. It is considered that the baseline, defined by RHS database, may have a potential to trigger deposition and that the cross-section will be filled with a layer of sediments across the whole width of the section reducing the available flow area. Several amounts of deposition have been considered in the calculations, based on reductions of flow area of 5, 10, 15, 20 and 25 percent.

A rule based on the concept of stream power was developed to identify watercourses where sedimentation processes might occur and thus, are likely to need to be maintained. It is understood that this general rule should be validated and updated locally with detailed knowledge of sedimentation processes. The stream power indicates the relative balance of energy in the river on a reach scale level and it is estimated as:

$$
\omega=\rho g Q S / B
$$

where $\omega$ is the stream power unit $(\mathrm{W} / \mathrm{m} 2), \rho$ is the specific weight of water $(\mathrm{kg} / \mathrm{m} 3), g$ is the acceleration due to gravity $(\mathrm{m} / \mathrm{s} 2), Q$ is the bankfull discharge, $S$ is the bankfull slope and $B$ is the channel width. The stream power has been used by geomorphologists and ecologists as a method of taking an initial decision on how a river channel might be potentially affected by processes of erosion or deposition [4,5]. The effective available stream power to move sediment downstream is obtained subtracting the critical power from the total available power:

$$
\omega_{e}=\omega-\omega_{c}
$$

where the sub index $e$ means excess and $c$ critical. A watercourse is identified as likely to have sedimentation problems if $\omega_{e}$ is negative, with $\omega_{c}=25 \mathrm{~W} / \mathrm{m}^{2}$. This is based on stream power values presented in $[4,5,6]$. It is stressed that this is an indicative value that could be updated with more detailed local knowledge. For example, it is not possible at a national level study and considering generic rules to identify the fine sediment that may enter watercourses via land drains, sewers outfalls and ditches.

Comparison of Options 1 and 2 provides an understanding of potential impacts of sediment management, without any vegetation management.

\begin{tabular}{|c|c|c|c|c|}
\hline \multirow{2}{*}{ Option } & \multirow{2}{*}{$\begin{array}{c}\text { Cross- } \\
\text { section } \\
\text { shape }\end{array}$} & \multicolumn{3}{|c|}{ Vegetation } \\
\cline { 3 - 5 } & Left bank & $\begin{array}{c}\text { Channel } \\
\text { bed }\end{array}$ & $\begin{array}{c}\text { Right } \\
\text { bank }\end{array}$ \\
\hline 1 & $\mathrm{BL}$ & $\mathrm{BL}$ & $\mathrm{BL}$ & $\mathrm{BL}$ \\
\hline 2 & Deposition & $\mathrm{BL}$ & $\mathrm{BL}$ & $\mathrm{BL}$ \\
\hline 3 & $\mathrm{BL}$ & $\mathrm{BL}$ & $\mathrm{BL}$ & $\mathrm{Cut}$ \\
\hline 4 & $\mathrm{BL}$ & $\mathrm{Cut}$ & $\mathrm{BL}$ & $\mathrm{BL}$ \\
\hline 5 & $\mathrm{BL}$ & $\mathrm{BL}$ & $\mathrm{Cut}$ & $\mathrm{BL}$ \\
\hline 6 & $\mathrm{BL}$ & $\mathrm{BL}$ & $\mathrm{Cut}$ & $\mathrm{Cut}$ \\
\hline 7 & $\mathrm{BL}$ & $\mathrm{Cut}$ & $\mathrm{Cut}$ & $\mathrm{BL}$ \\
\hline
\end{tabular}

Table 1. Management options considered (BL $=$ Baseline as defined by RHS)

Options 3 to 7 consider different scenarios of vegetation management on banks and/or channel bed. The change in roughness coefficient associated to cutting is defined as per Table 2 . 


\begin{tabular}{|c|c|c|}
\hline Location & Description & $\begin{array}{c}\text { Roughness } \\
\text { vegetation }\end{array}$ \\
\hline Bank & $\begin{array}{c}\text { Whatever vegetation was } \\
\text { defined as 'Base line' is } \\
\text { considered to be cut to the } \\
\text { level of a turf grass }\end{array}$ & 0.021 \\
\hline $\begin{array}{c}\text { Channel } \\
\text { width }<2 \mathrm{~m}\end{array}$ & $\begin{array}{c}\text { The vegetation in the } \\
\text { whole channel width is } \\
\text { removed }\end{array}$ & 0 \\
\hline $\begin{array}{c}\text { Channel } \\
\text { width }<5 \mathrm{~m}\end{array}$ & $\begin{array}{c}\text { The vegetation in } 80 \% \text { of } \\
\text { the channel width is } \\
\text { removed }\end{array}$ & 0 \\
\hline $\begin{array}{c}\text { Channel } \\
\text { width }<5 \mathrm{~m}\end{array}$ & $\begin{array}{c}\text { The vegetation in } 50 \% \text { of } \\
\text { the channel width is } \\
\text { removed }\end{array}$ & 0 \\
\hline
\end{tabular}

Table 2. Definition of roughness values for vegetation cut in the channel and banks

Comparison of Options 3 to 7 with Option 1 (Do nothing) provides an understanding of the impacts of vegetation management. Comparison with Option 2 provides an understanding of the impacts of sediment and vegetation management all together.

Additional management options were also considered to further explore the impacts of sediment management. These options however, are not reported here.

\section{How impacts of conveyance are quantified}

The difference between in-channel discharges in the "with" and "without" (or "Do nothing") management scenarios provides an understanding of the magnitude of the impacts of maintenance works. The increase of discharge can be expressed as a percentage when divided by the discharge "without" maintenance and thus, the measure to quantify the impact of maintenance is defined as:

$$
\Delta \mathrm{Q}(\%)=\left(\mathrm{Q}_{\text {with }}-\mathrm{Q}_{\text {without }}\right) / \mathrm{Q}_{\text {without }}
$$

where $\Delta \mathrm{Q}$ is the increase in channel discharge in the main channel (expressed as a percentage), $Q_{\text {without }}$ is the in-channel water discharge without maintenance works and $\mathrm{Q}_{\text {with }}$ the in-channel discharge with maintenance.

This metric is adopted to express the impacts of channel maintenance as it describes the impacts in a simple and credible way, easy to communicate.

Higher increases are expected for lower in-channel discharges (higher frequency events). If the main channel is large and can convey large discharges, it is likely that the impacts of maintenance would be minor. It is not expected that maintenance works in the channel will modify substantially the likelihood of flooding during large events. Flood risk measures such as defences, training works and flood storage areas may be better options to ensure an appropriate protection.

Estimating water discharges with and without maintenance requires hydraulic calculations to assess the channel capacity. This implies the use of hydraulic models, the definition of the representative cross-section geometry as well as of roughness coefficients.

The Conveyance Estimation System (CES) [3] is used to estimate water discharges associated to water levels at each cross-section for a range of flood events. The calculation approach in CES for estimating conveyance is based on the depth-integrated Reynolds Averaged Navier-Stokes equations in the streamwise direction. Water discharges are considered separately in the inchannel and the floodplains. The input files necessary to run CES are created with the geometric data and roughness coefficients.

Data from the River Habitat Survey (RHS) is used to define the channel cross-section. This database stores information about the shape and dimensions of the main channels, recorded during site inspections. It also defines the type of floodplain that has been idealised in this approach as triangular sections with different slopes. The spread of the RHS field samples to create the database covers the whole country and this information has been used to recreate the cross-section shapes. It is recognized however, that information may not be accurate in some areas.

Roughness coefficients are also defined based on information from RHS. In this dataset, ten observations of the type of channel and bank vegetation are taken at each sampling location. The data is analysed and the most common type is computed. RHS also defines the type of substrate. The total roughness of cross-sections is defined as the combination of substrate and vegetation roughness in the following way:

$$
n=\left(n_{s}+n_{v}\right)^{1 / 2}
$$

where $n$ is the total roughness coefficient and $n_{s}$ and $n_{v}$ are substrate and vegetation roughness coefficients respectively.

Figure 4 shows an example of the type of results obtained.

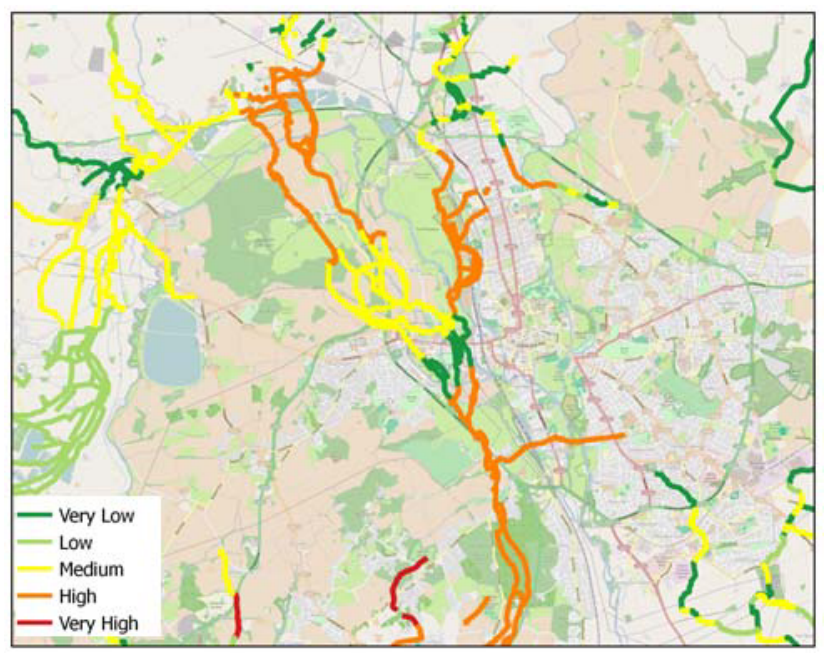

Figure 4. Example of results showing the benefit of a particular maintenance option along watercourses 


\section{How benefits of conveyance are quantified}

To estimate the 'potentially important benefitting watercourses' the relative importance of each length is estimated by associating the individual 'properties at risk' to individual watercourse lengths. Other metrics could be used to estimate the benefits, such as agricultural land, environmental sensitive sites, critical infrastructures, etc., for this application, the main concern is related to the individual residential properties (households).

Several national datasets and pre-processes are needed in order to assess watercourse criticality. The whole area of interest, which includes watercourses and floodplains (as already identified in the UK National Flood Risk Assessments, [7]) is divided in cells with dimensions of $50 \mathrm{~m} \times 50 \mathrm{~m}$.

The definition of main watercourses is obtained from a Detailed River Network (DRN) provided by the Environment Agency. All connected watercourses in the DRN are divided into $50 \mathrm{~m}$ sections.

Residential properties in the National Receptors Dataset have been converted from points in a shapefile to a grid of data by aggregating the centroids of the properties onto cells with a dimensions of $50 \mathrm{~m} \times 50 \mathrm{~m}$.

The length of watercourse responsible for flooding any given floodplain cell, is assumed to be the closest watercourse. By checking the distance from every flooding property to the centroid of every $50 \mathrm{~m}$ length of watercourse, we can find the section of river that is closest to every flooding property. Our methodology involves assigning the benefit at the flooding property to the closest sections of watercourse. Corrections are introduced to also take into account the elevation of the floodplain cells (in relation to the watercourse). Our approach is a simplification of a "true" spreading model and therefore, additional assumptions were considered in order to limit the area that can be flooded by any given watercourse cell.

The number of residential properties that can be flooded by a $50 \mathrm{~m}$ length of watercourse is stored (Figure 5) taking into account its distance to the particular length of watercourse and its elevation.

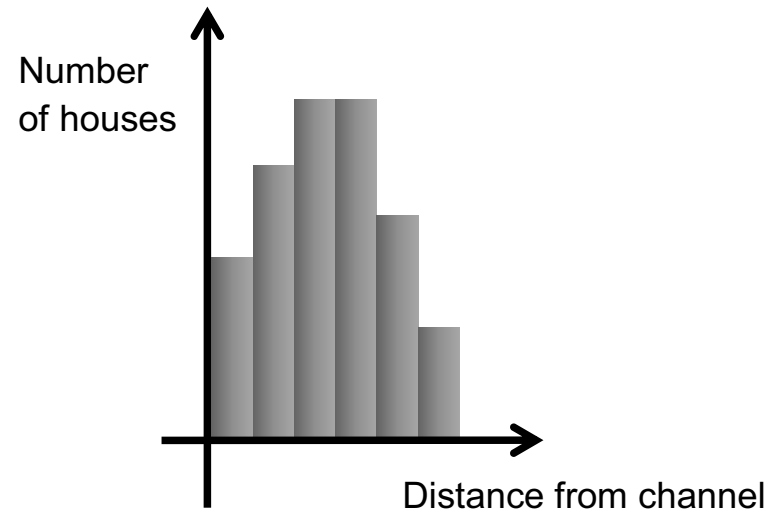

Figure 5. Histogram of number of houses at different distances of the watercourse
To estimate the number of houses benefiting from maintenance, the distances of flooded areas from the channel for a range of discharges in the "maintained" and "non-maintained" scenarios are compared. These distances are used to accrue the benefits of maintenance. Figure 6 shows how the differences in the length of flooded area are decreasing as discharge increases.

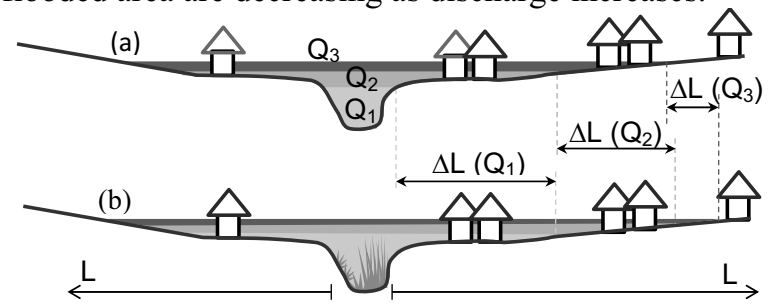

Figure 6. Increase of floodplain length at risk of flooding, $\Delta L$, for 3 discharges, $Q i$, with (a) and without (b) maintenance

The information is used to identify the number of houses benefitting from each management scenario (Options 2 to 7 in Table 1) when compared with the no maintenance scenario (Option 1).

\section{Selection of the preferred maintenance option}

The selection of the preferred maintenance option is based on the coincidence of the attributes in a watercourse length of the highest impacts of conveyance management (as defined in Section 3) and highest benefits associated to the watercourse (as defined in Section 4). When the impacts of conveyance management are high, the difference in the length of floodplain impacted by the works is also large and thus, the possible number of properties benefiting from maintenance could also be large although it always depend on the distribution of properties in the floodplain.

In order to select the preferred maintenance option, the benefits of applying a particular option should be compared with the costs to implement it. The costs, expressed in monetary terms $(\mathfrak{f})$, of a flooded house defined by [7], are considered the benefits that would be obtained if maintenance works were performed. Information provided by the Environment Agency is used to estimate the costs of vegetation maintenance works, defined as pounds per meter. The ratio between Benefits and Costs is used to select the preferred maintenance option in a particular watercourse, which is the one with the largest ratio

In the case of dredging, it is not possible to define a cost of the works at national level due to the large differences depending on the characteristics of the site. The costing of this type of operations also need to take into account the disposal of material off site, which could have large variations. Therefore, vegetation and dredging operations were not compared.

The following figure shows an example of the type of results obtained. The large circles show the type of intervention (whether grass, weed, grass \& weed or dredging). 


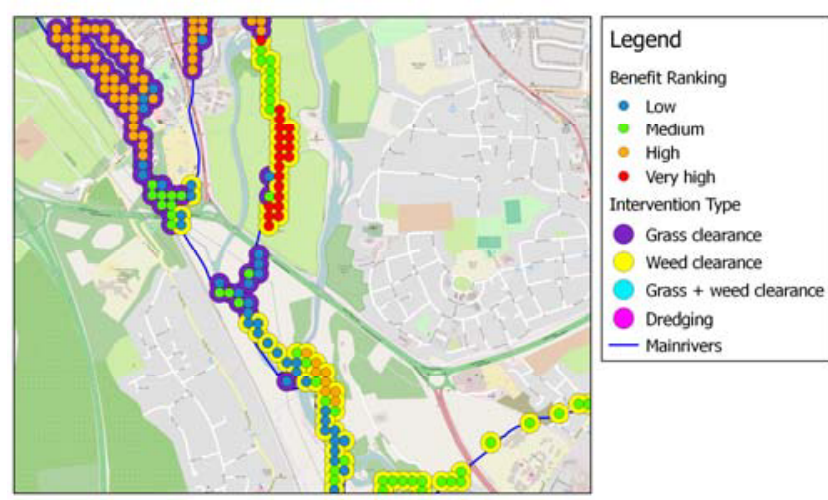

Figure 7. Example of results with the type of recommended intervention (big circle) and the amount of benefit (small circle)

\section{Discussion of results}

The methodology presented provides a scientificbased approach to estimate the benefits of conveyance maintenance operations at national level. It helps to identify where maintenance works can have a real impact on water levels and whether this change effectively modifies the risk of flooding of the surrounding properties. The aim of the work is to support the decision-making process in the Environment Agency in UK. Due to the financial burden associated with maintenance it is necessary to ensure that money is spent where it provides the largest benefits.

The development of a national methodology, based on general input datasets, necessarily implies the consideration of assumptions that increase the uncertainty of results.

One of the main sources of uncertainty is related to the definition of cross-sections geometry, based on national databases. It is acknowledge that information provided by local surveys can be a more reliable source of data. If available, this information could be used in the method explained and therefore, reduce the uncertainty of results.

Rules have been developed to decide the likely management options applied to a river watercourse. They are based on its type of vegetation and stream power. It has to be recognized that this selection is somewhat arbitrary and dependent on the available input information. It is not possible to capture the particularities of each location in a study at national level, nor is such type of local information readily available. The rules developed are based on the best science and guidance available rather than on local conditions of a site.

The benefits of maintenance are calculated at a particular point in time: just after performing the works. It is expected that vegetation will grow during the year and thus, benefits will decrease with time. No temporal evolution has been considered in the results presented. Similarly, the benefits of sediment management are likely to expand over a few years, until the deposits grow again. At this stage, the method suggested does not consider time evolution.
A simplified flood spreading model is used to estimate the residential properties flooded in both scenarios, with and without maintenance. It could be possible to use more sophisticated methods such as the one used in the National Assessment of Flood Risk in England [8].

\section{References}

1. http: ://www.riverhabitatsurvey.org/

2. Environment Agency (2012) Delivering Consistent standards for sustainable asset management. FCRM Asset Management. Maintenance Standards. Version 2 March 2012

3. Defra/Environment Agency (2004) Reducing uncertainty in river flood conveyance, Phase 2 . Conveyance Manual Project record W5A-057/PR/1

4. Jacobs (2007). A guide to the use of the Stream Power Tool in River Management. Preliminary User Guide.

5. Wallerstein, N.P., Soar, P.J., Thorne, C.R. (2006) River Energy Auditing Scheme (REAS for catchment flood management planning. Proceedings of the International Conference on Fluvial Hydraulics, Lisbon, Portugal, 6-8 September. River Flow 2006.

6. Annandale, G.W. (2006). Scour Technology: Mechanics and Engineering Practice. New York. McGraw-Hill.

7. Penning-Rowsell, E., Johnson, C., Tunstall, S., Tapsell, S., Morris, J., Chatterton, J., Green C. (2005) The benefits of flood and coastal risk management: a manual of assessment techniques. Published by Middlesex University Press

8. Jamieson S, Lhomme J, Wright G, Gouldby B. (2012). A highly efficient 2D flood model with subelement topography. Proceedings of the Institution of Civil Engineers-Water Management, v. 165, n. 10, p. 581-595. 